\title{
COLLABORATING AND DISSEMINATING SCIENCE: SHARING IDEAS, PROJECTS AND LEARNINGS - PROF. (HP) DR. LAMANAUSKAS (A LITHUANIAN) IN SOUTH AFRICA
}

\author{
Angela James \\ University of KwaZulu-Natal, South Africa
}

In South Africa, Education policy documents abound with statements promoting scientific and technology literacy (DoE, 2002). In spite of this demand, a global trend is developing which reveals a sharp decline in students who are interested in the natural sciences (Areepattamannil, Freeman \& Klinger, 2010). In an effort to increase students' interest in Science, various mechanisms are employed both nationally and internationally. Also, the effective, contextually related implementation of Natural Sciences in the Foundation, Intermediate and Senior schooling phases is a problematic that is presently being researched, and programmes for the professional development of student teachers are being revised to respond to this issue. The re-curriculation of all programmes at UKZN, School of Education re-focuses our efforts in curriculum design on how to teach Natural Sciences in schools, in preparing learners for the 21st century. Our current countries' responses to external testing TIMMS bears strong evidence for a need to intervene and explore avenues to effectively engaging Natural Sciences teachers and researchers in tertiary institutions on actions to be planned and implemented. In these initiatives an important aspect to consider is the role of teachers as they are regarded as the change agents in any education system. In exploring teacher intervention initiatives, Dr Angela James applied to the National Research Foundation for funding to invite Prof. (HP) Dr. Vincentas Lamanauskas, Director of the Scientia Socialis, Chairman of the Scientific Methodical Centre "Scientia Educologic, and Professor and Head researcher at Šiauliai University, Lithuania to South Africa.

Prof. Lamanauskas is a specialist in his field of Natural Science education in Central and Eastern Europe, where he has explored teaching, learning, and engaged in collaborative research on researching and promoting Natural Sciences. He was invited to South Africa to engage and collaborate with researchers in Natural Science education and to initiate research in the field. In developing and disseminating research, his work in writing and publishing is significant, as he has an extensive list of articles, is an Editor in Chief of eight international journals, member of the Editorial Board of ten international journals, presented many workshops, and works collaboratively with international colleagues on the preparation of scientific articles and academic writing for journals. Since the collaboration also focused on research projects, his expertise in the European Union programme HORIZON2020 and at the Agency for Science, Innovation and Technology (MITA) in Lithuania served to inform on the funding and signing of a Memorandum of Understanding between the University of KwaZulu-Natal and Šiauliai University.

Prof. Lamanauskas arrived in South Africa, at O. R. Tambo International Airport, in Johannesburg, on the $14^{\text {th }}$ January and was whisked directly to the South African Association of Mathematics, Science and Technology Education (SAARMSTE) Conference, in Pretoria. This is an annual conference, in January, for teachers and researchers in the fields of Mathematics, Science and Technology education. The conference organisers requested that he present at the conference that afternoon. His presentation on SCIENCE 
AND MATH TEACHERS' COLLABORATION FOR BETTER RESULTS: MaT²Smc PROJECT was well received and the wealth of information shared indicated the extensive work that the collaboration had achieved. He met and discussed with many researchers at the conference and also interviewed some participants. Africa is an interesting continent and indigenous knowledge plays a major role in the lives of many people. Appreciating cultural, indigenous and living knowledge as the basis for the knowledge developed, gives credibility to knowledge production in academia. The conference has not ended if the SAARMSTE Choir has not sung and the Celebration dinner is not celebrated. The choir with "SAARMSTE OUR SAARMSTE" in different voices captured the hearts and spirit of all. Our Minister of Science and Technology, Dr Naledi Pandor was the invited guest at the dinner. Her speech was concise and captured the context of South African education, and the role that we can play in conserving our environments and mitigating the effects of climate change. Prof. Lamanauskas learnt so much about the developments in Science and Technology in South Africa - alternative energy innovations and astronomy. It is often said that Professors at a social function is something else. .. see Prof's moves on the dance floor...

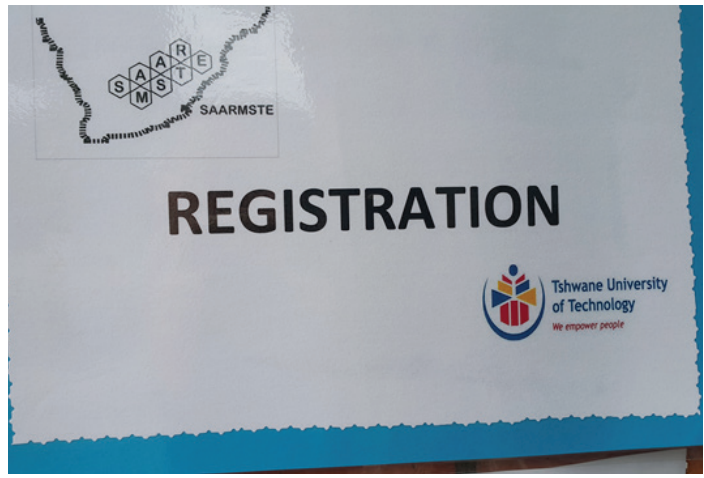

Figure 1. The conference registration desk at Tshwane University of Technology in Pretoria.

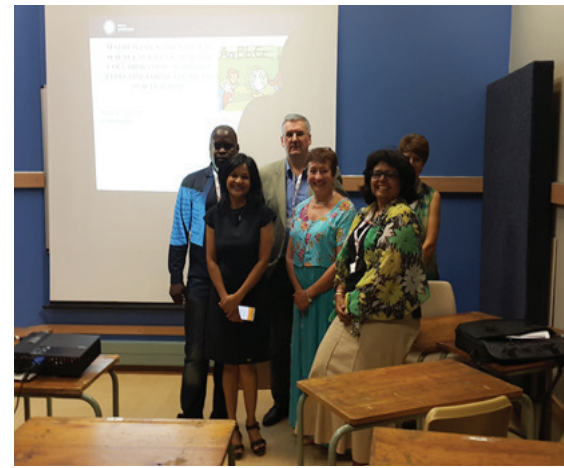

Figure 2. Evidence of Prof Lamanauskas's presentation.

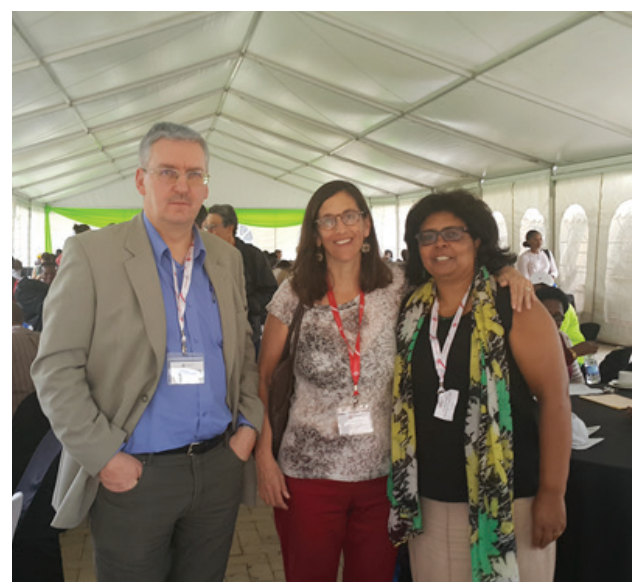

Figure 3. Prof Lamanauskas; Prof Karin Brodie; Dr Angela James (lunchtime and socializing).

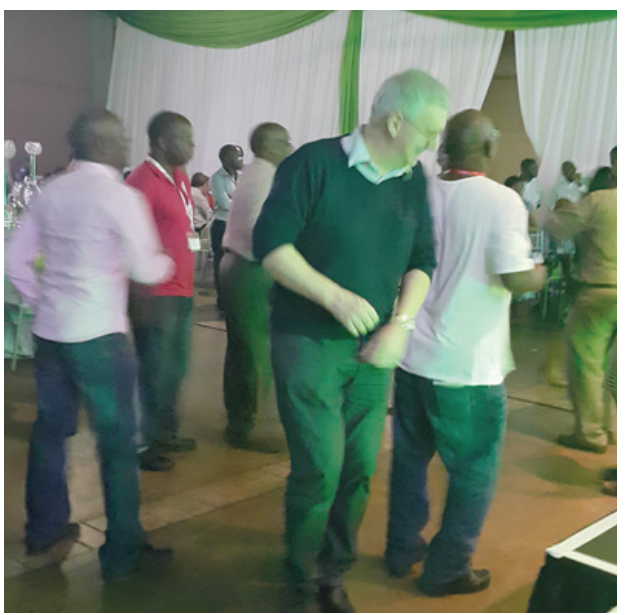

Figure 4. Prof Lamanauskas making his moves on the dance floor. 
A visit to South Africa is not complete (if you can fit it in) a visit to the Cradle of Humankind. It is a World Heritage Site, declared since 1999. It occupies 47000 hectares (180 sq miles), where the 2.3 million year old fossil, Autralopithecus africanus (nicknamed 'Mrs Ples') and more recently Homo naledi were discovered. The site has rolling hills and standing in the area gives the spirit of awesomeness.

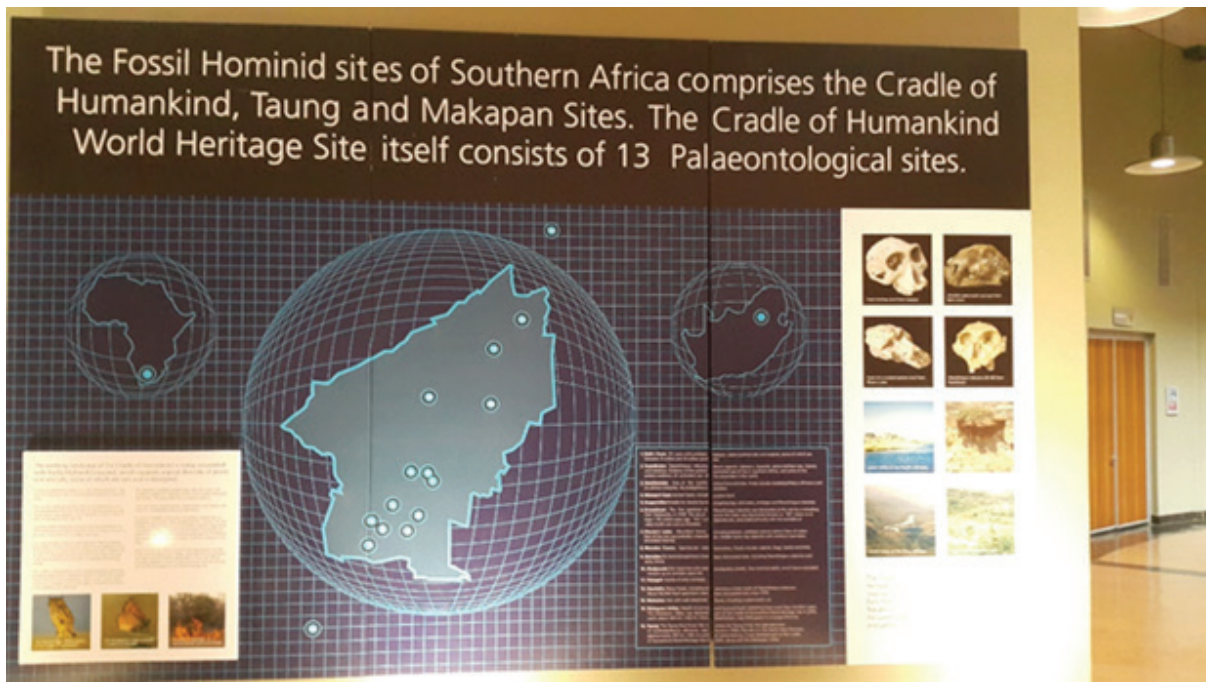

Figure 5. The Cradle of Humankind - display.

The learning and engagement on this trip was phenomenal where even a tortoise was rescued from being run over by a car on a national road. The nature reserves and parks are extensive in South Africa, but unfortunately a trip to these places was not possible. As environmentalists, a particular environmental centre in the Central Drakensberg is one that we visited - Entabeni. A surprise statement was that there is a student from (Estonia) working at the centre. The global village of the world is so immense and interconnected. Student exchanges should be on the move more and more and it is in these types of exchanges and the signing of Memorandums of Understanding that our universities can collaborate for the greater good for all. 


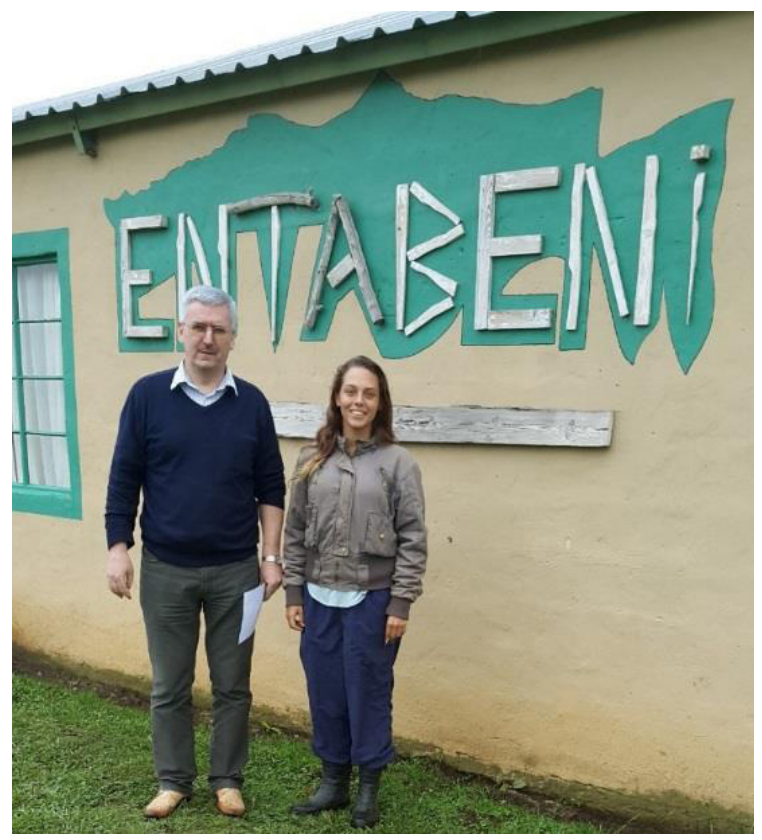

Figure 6. Prof Lamanauskas with a field officer at Entabeni Communications Environmental Education Centre.

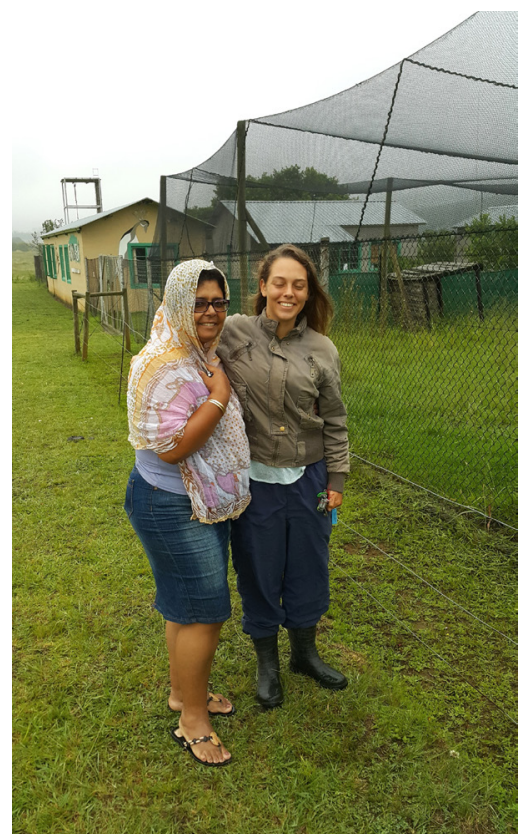

Figure 7. Dr Angela James with a field officer.

His visit to and work at UKZN concerned a university-wide presentation for the University Teaching and Learning Office (UTLO) on "A MULTIDIMENSIONAL MODEL FOR THE EXPLORATION OF POSITIVE AND NEGATIVE EFFECTS OF SOCIAL NETWORKING WEBSITES AS PERCEIVED BY STUDENTS.” Reflecting on the seminar, Professor Lamanauskas said, "I really enjoyed presenting the workshop, and more so the questions and collaboration. I am glad that the academics are interested and willing to engage around social media." Staff present indicated the importance of strategies to consider when using ICT and the 'Flipped Classroom' ideas were shared. This presentation raised many discussions among colleagues about how to engage students on a deeper level using our learning management system (LMS - MOODLE). The video recording of Professor Lamanauskas' seminar is available on the Teaching \& Learning TV YouTube channel at www.youtube.com/utlotv 


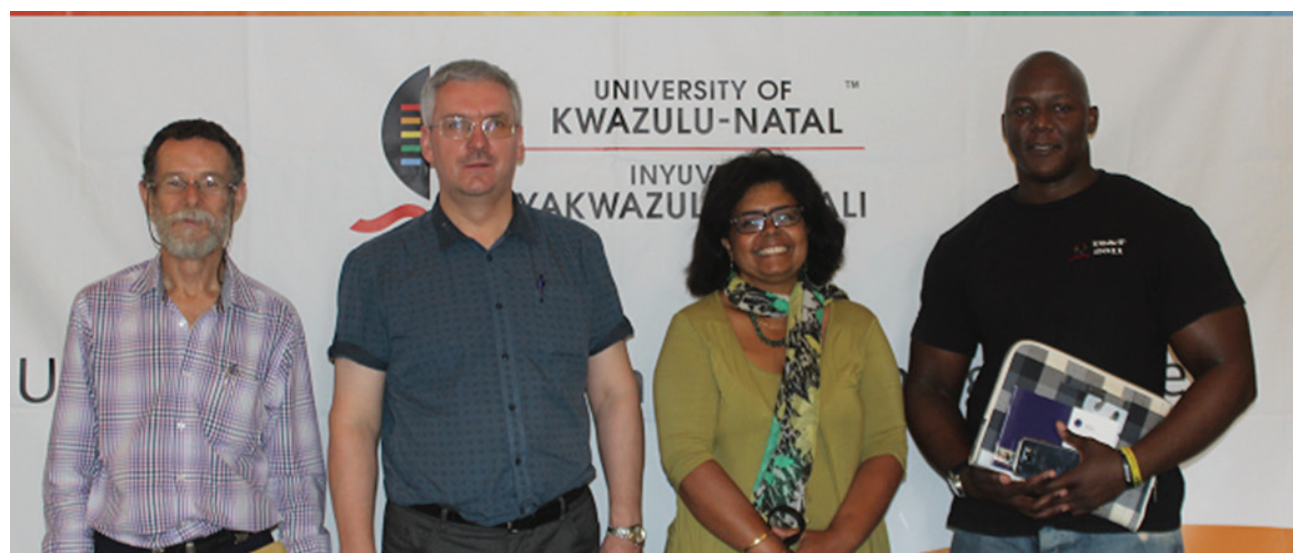

Figure 8. Students' use of social media explored at UTLO seminar.

The three days spent at UKZN were busy, but interesting and exciting. Professor Lamanauskas met with the Dean of the School of Education, Professor Kamwendo and had a welcome tea with academics from the Science and Technology Cluster, School of Education. And it was back to work on Tuesday when he presented two talks to UKZN staff - SCIENCE AND MATH TEACHERS COLLABORATION FOR BETTER RESULTS: $\mathrm{MaT}^{2} \mathrm{Smc}$ PROJECT; and ACADEMIC WRITING, RESEARCH METHODOLOGY AND SCIENTIFIC PUBLISHING. The academics expressed their immense gratitude for the sharing of resources and the information on how this large project was designed and implemented. What was striking was the number of partners in the project and the specific role that each one played. This presentation confirmed for us the importance of funding for large projects, the accountability on the part of researchers, and the possibility of producing a phenomenal set of resources, in a team. Many research students and academics attended the research talk, which in a few slides presented the methodological research aspects as doable, systematic and informative. Professor Lamanauskas presented and shared his slides with the academics, as resources as well and the work at a university with reference to community engagement also entails working with non-governmental organisations (NGOs) for our community engagement. An NGO that has engaged many teachers in teacher professional development and has worked with learners as well - it is A World Class Centre for Advancing Science and Mathematics Education. Prof Lamanauskas engaged with the Operations Manager, Mr Henre Benson - sharing the initiatives and projects that the organisation works on, with communities, one of which is a special project where Science is taken to communities in a mobile laboratory - Science to Go. Since this visit and because Prof Lamanauskas saw a poster with a request for calculators, he has sent these to the organisation. On Friday, 5 February 2016 just after Prof Lamanauskas's trip, CASME in partnership with MAHLE, achieved the momentous task of bringing together 2104 learners, teachers, UKZN students and staff to conduct the World's Largest Practical Science Lesson.

Prof Lamanauskas also presented to the Natural Sciences academic staff at the Mangosuthu University of Technology (MUT). The presentations raised issues of research and the possible topics that could be explored further. During the thank you tea, the academics expressed their appreciation for the input and expressed the wish for a great collaboration between UKZN and MUT and Šiauliai University in the future. 


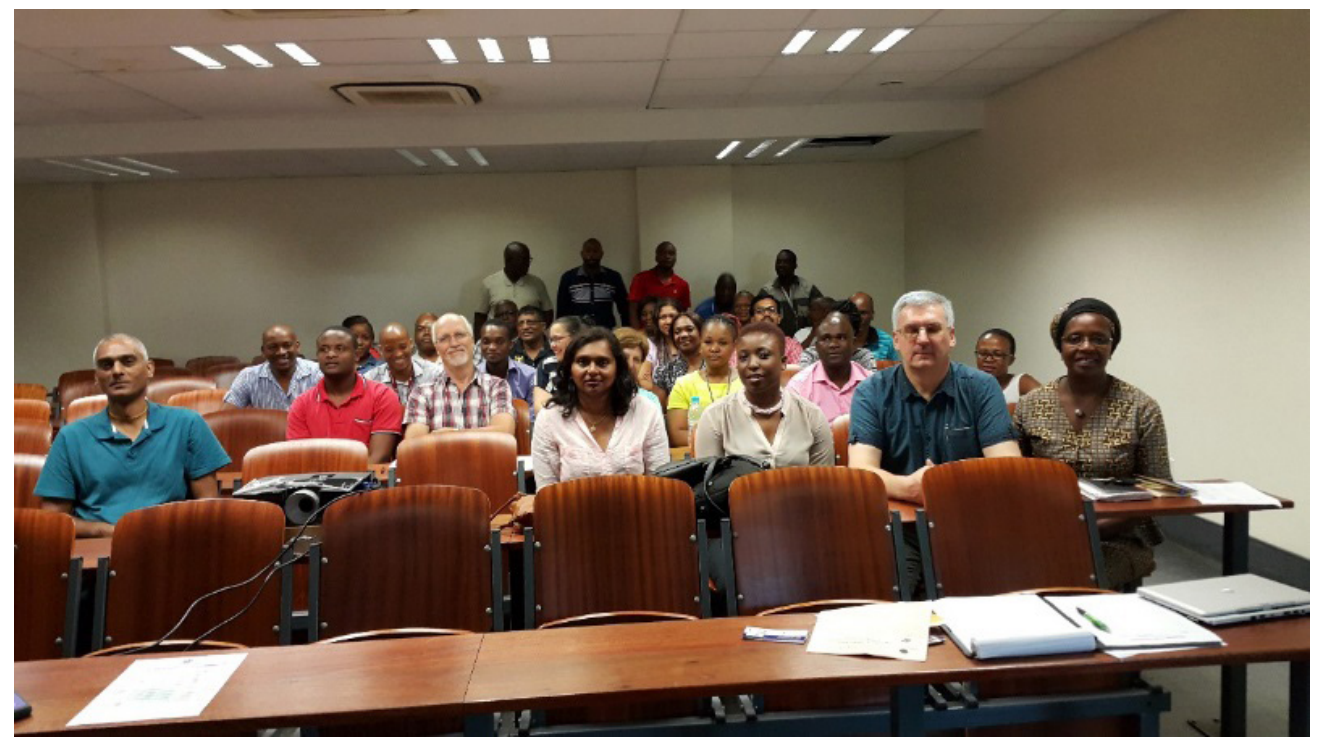

Figure 9. MUT staff after the two presentations.

A person cannot come to Durban and leave without eating our famous food, a Bunny chow. So, before departing Prof Lamanauskas ate our famous food, with lots of water the chillies were too hot. Neither can a person come and not go to Ushaka - to fight the Anaconda. He did it!

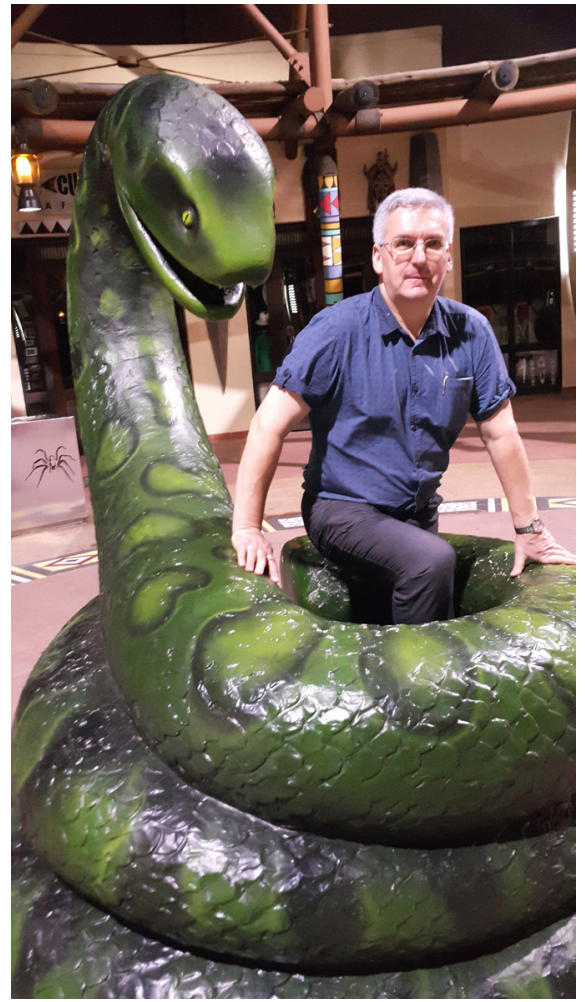

Figure 10. "Fight with the Anaconda".

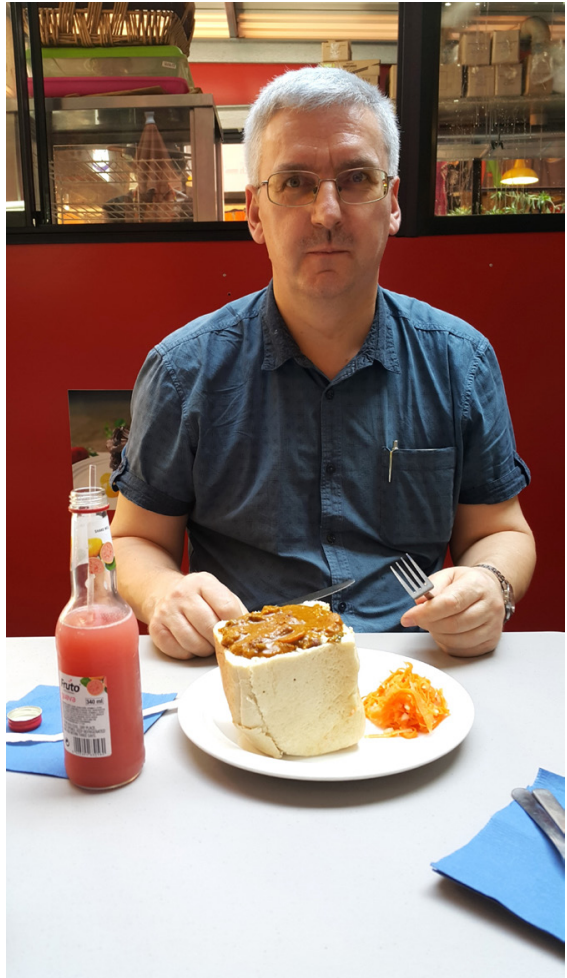

Figure 11. Famous food - a Bunnychow. 
In conclusion, the wealth of collaboration is an aspect that we all need to work with to a greater extent. The sharing and intense engagement was so enriching for all who were engaged in any part of this collaborative venture. So, South Africa, why would you want to go there? A great place and exceptionally wonderful people - we share, learn and show gratitude. This has been a phenomenal experience and I must say I am so thankful to Prof Lamanauskas for his willingness to travel to unknown places (where lions roam the streets) and to be so engaging with all whom he came into contact with.

I do show appreciation and I thank the South African National Research Foundation who funded this trip thorough the KIC Grant (NRF/KIC).

\begin{tabular}{l}
\hline Angela James \\
PhD., Cluster Leader in Science and Technology Education, Senior Lecturer, Co-Faculty Advisor: \\
ENACTUS, CU 139, Main Administration \& Tutorial Building, University of KwaZulu-Natal, \\
Edgewood Campus, Durban, South Africa. \\
E-mail: jamesa1@ukzn.ac.za
\end{tabular}

